\begin{tabular}{|l|c|c|c|c|c|}
\hline J. Tek. Ling & Vol.11 & No.1 & Hal. 71 - 77 & Jakarta, Januari 2010 & ISSN 1441-318X \\
\hline
\end{tabular}

\title{
PENGHITUNGAN EMISI KARBON DARI LIMA SEKTOR PEMBANGUNAN BERDASAR METODE IPCC DENGAN VERIFIKASI FAKTOR EMISI DAN DATA AKTIVITAS LOKAL
}

\author{
Wahyu Purwanta \\ Peneliti di Pusat Teknologi Lingkungan \\ Badan Pengkajian dan Penerapan Teknologi
}

\begin{abstract}
After ratifying the Kyoto Protocol, Indonesia has obligation to make report on National GHGs emission for UNFCCC. There are some studies at national level related to GHGs inventory. In this study we calculated $\mathrm{GHG}\left(\mathrm{CO}_{2}\right.$ and $\left.\mathrm{CH}_{4}\right)$ emissions from 5 (five) sectors i.e forestry, energy, industry, agriculture and waste. Calculation use 2006 IPCC method with local values for verification or enhanced the Tier of method. The local values are, forestry allometric equation, emission factor of paddy field, generation and composition of municipal solid waste, solid waste management as well. Calculation result of GHGs emission in this study is $827,058 \mathrm{Gg} /$ year in the term of $\mathrm{CO}_{2}$ equivalent. This numbers is estimated arround $60 \%$ of the realistic numbers due to the accuracy of the transportation data and unaccounted peat fire data in the study. Carbon emission from peat fire is the biggest emission. From all sector has calculated, forestry sector is the biggest $\mathrm{CO}_{2} \mathrm{e}$ emmitor with contribute arround $58 \%$, follow energy sector (25\%), agriculture (8\% ), industry sector (6\%), and waste sector (3\%). The proportion of distribution each sector can change if the data more broad the calculation include more detail in sub sectors.
\end{abstract}

Key words : GHGs Emissions, Local Values, Sector Contribution

\section{PENDAHULUAN}

\subsection{Latar Belakang}

Indonesia sudah meratifikasi Protokol Kyoto melalui UU No.17 Tahun 2004, dan tidak termasuk dalam negara yang harus mengurangi emisi tetapi dapat berperan dalam mitigasi pemanasan global melalui Mekanisme Pembangunan Bersih (CDM) sebagai host country bagi proyek-proyek pengurangan Gas Rumah Kaca (GRK). Karena itulah, sangat penting bagi Indonesia untuk mengkaji berapa besar kemampuan alam maupun berbagai aktivitas sektoral di Indonesia dalam 'menyumbang' (source) maupun 'menyerap' (sink) GRK. Untuk itu sebagai langkah awal berbagai tindakan mitigasi GRK, penting bagi Indonesia untuk memiliki data dasar (baseline) emisi karbon dari beberapa sektor pembangunan (sector based emissions).

Penyusunan data emisi GRK pada dasarnya adalah aktivitas manajemen data dan merupakan bagian utama dari kegiatan pengkajian GRK. Keberadaan data emisi GRK secara nasional akan memberi arah bagi pengambilan kebijakan pembangunan. Hal ini disampaikan dalam UNFCC Article 2 “.. stabilisasi konsentrasi GRK di atmosfer pada tingkat aman ... " dimana tingkat aman menurut IPCC adalah $450-550$ $\mathrm{ppm}^{1)}$. Pada dasarnya upaya inventarisasi emisi GRK juga akan berguna dalam 
hal tindakan pengurangan emisi melalui instrumen ekonomi (misal Certified Emission Reduction). Inventarisasi emisi GRK maupun potensi Carbon Sink-nya akan sangat berguna bagi Indonesia dalam perundinganperundingan atau negosiasi internasional terlebih berdasar pengalaman pernah ada isu bahwa Indonesia adalah emitor terbesar ke tiga di dunia terkait dengan seringnya terjadi kebakaran hutan ${ }^{2}$. Hal-hal seperti ini hanya bisa dicounter dengan data-data yang akurat.

Tulisan ini mencoba memaparkan hasil penghitungan emisi karbon dari lima sektor yakni sektor kehutanan, sektor pertanian, sektor energi, sektor industri dan sektor limbah. Data-data diperoleh baik dari pengamatan langsung maupun data sekunder dari instansi terkait dan diolah dengan formula IPCC Calculation Method yang sudah disepakati (approved) banyak negara. Pengukuran atau survey langsung dilakukan terhadap 'activity data' maupun faktor emisi bertujuan agar kualitas penghitungan lebih mendekati angka sebenarnya atau sesuai kondisi Indonesia. 'Activity data' adalah data tingkat produksi, tingkat pemakaian atau kuantitas lain yang dinyatakan dalam berat.

\subsection{Tujuan}

Penelitian ini bertujuan menghitung emisi GRK khususnya dari sektor kehutanan, sektor pertanian, sektor energi, sektor industri dan sektor limbah, dengan mengukur langsung angka-angka faktor emisi pada tiap sektor.

\section{METODOLOGI}

Metode penghitungan emisi dan atau sink karbon (GHGs source-sink inventory) terus berkembang dari waktu ke waktu seiring dengan kemajuan verifikasi setiap parameter maupun konstanta tertentu bagi tiap negara. Intergovernmental Panel on Climate Change (IPCC) selalu merilis metode ini untuk tiap sektor dan selalu direvisi tiap tahun dalam dokumen IPCC Guideline for National Green
House Gases Inventories. Pembagian sektor dalam IPCC agak sedikit berbeda dengan yang dilakukan dalam studi ini namun metode yang digunakan tetap mengacu pada metode yang dikembangkan IPCC dan diverifikasi dengan pengukuran-pengukuran lapangan sehingga didapatkan konstantakonstanta yang tepat untuk Indonesia.

\section{a. Sektor Kehutanan}

Metode penghitungan kesetimbangan karbon di hutan dapat didekati dengan "Biomass Stock Approach" dan "Flow Approach". Dalam Biomass Stock Approach total stok karbon hutan netto didasarkan pada dua point asumsi ${ }^{3)}$ :

Net penurunan stok karbon hutan $=$ Net emisi $\mathrm{CO}_{2}$

Net kenaikan stok karbon hutan $=$ Net sink $\mathrm{CO}_{2}$

Dalam Flow Approach, perubahan tahunan dalam stok karbon hutan dihitung dengan mengestimasi fluks karbon pertumbuhan dan penyisihan biomassa tahunan, dan dihubungkan dengan perubahan di tanah. Umumnya pendugaan biomassa di lapangan dilakukan dengan menggunakan persamaan alometrik. Biomassa yang diukur umumnya berupa biomassa pohon tegakan (diatas permukaan tanah) yang dihitung berdasarkan penjumlahan biomassa batang, cabang dan daun. Setelah seluruh berat biomasa dihitung, maka dilakukan penjumlahan total biomasa dengan rumus sbb:

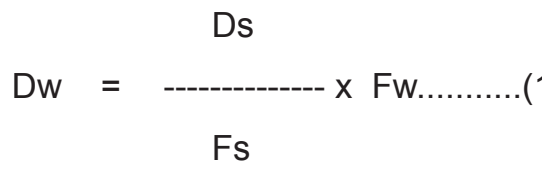

Dimana:

Dw : seluruh berat kering

Ds : berat kering sampel

Df : berat sampel segar

Fw : seluruh berat segar 
Setelah mendapatkan seluruh data dari setiap plot, maka seluruh sensus pohon dihitung sbb:

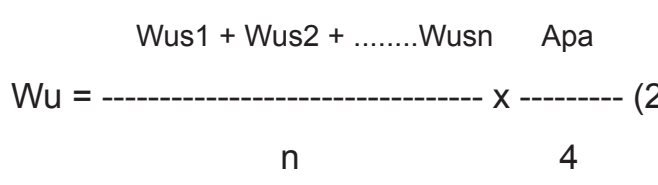

dimana

Wu : berat kering biomass dibawah tanah per plot

Dw : berat kering sample no.1

Dw : berat kering sample no.2

Dw : berat kering sample no.n

Apa : Luas plot untuk semua pohon $\left(\mathrm{m}^{2}\right)$

Alometri adalah hubungan antara pertumbuhan beberapa bagian yang berbeda dari tanaman, yaitu khususnya hubungan antara diameter pohon (setinggi dada), tinggi, dan berat kering dari suatu tanaman. Persamaan alometri ini digunakan untuk melakukan estimasi dari suatu biomasa, dimana setelah persamaan alometri diketahui, maka biomasa total dari suatu tegakan dalam hutan dapat diperkirakan besarnya, hanya dengan mengukur diameter suatu jenis pohon.

Setelah diketahui jumlah stok biomasa disuatu area, dilakukan perkiraan kandungan karbonnya dengan dikalikan faktor kandungan karbon yaitu ekivalen $45 \%-55 \%$. Selanjutnya untuk mengetahui besar emisi karbon, yaitu dengan memperhitungkan berat molekul $\mathrm{C}$, sehingga kandungan karbon tersebut dikali dengan faktor $44 / 12 \mathrm{CO}_{2}$.

Dengan metode ini tampaknya cukup mudah diterapkan dengan hasil yang baik. Peralatan yang digunakan untuk pengukuran dilapangan juga relatif sederhana, demikian juga cara perhitungannya tidak rumit. Apabila semua jenis tanaman hutan sudah diketahui persamaan alometrinya, maka akan semakin memudahkan melakukan estimasi emisi karbon dari sektor kehutanan. Faktor lokal yang digunakan dalam penelitian ini adalah persamaan alomatrik untuk hutan di Kabupaten Siak (Riau).

\section{b. Sektor Pertanian}

Dalam tulisan ini, sektor pertanian meliputi penghitungan emisi $\mathrm{CH}_{4}$ dari peternakan (enteric fermentation dan manure management) serta lahan sawah (paddy field). Formula untuk emisi dari enteric fermentation adalah ${ }^{2)}$;

\begin{tabular}{|c|c|}
\hline \multicolumn{2}{|c|}{ dimana, } \\
\hline$E F(T)$ & $\begin{array}{l}=\text { faktor emisi tiap spesies ternak, } \\
\text { kg CH} / \text { ekor/thn }\end{array}$ \\
\hline$N(T)$ & $=$ jumlah ternak tiap spesies $(T)$ \\
\hline $\mathrm{T}$ & $=$ spesies/jenis ternak \\
\hline
\end{tabular}

Untuk manure management, juga digunakan persamaan (3) dengan nilai faktor emisi tiap jenis ternak EF(T) yang berbeda. Sedangkan untuk emisi dari lahan sawah (padi) digunakan formula perhitungan sbb;

$$
\begin{aligned}
& \text { Emisi } \mathrm{CH} 4=\mathrm{A} \text { * CFsoil * SFwater regime * } \\
& \text { EFpadi Gg/tahun ........................... (4) } \\
& \text { dimana, } \\
& \mathrm{A}=\text { luas lahan sawah }(\mathrm{Ha}) \\
& \mathrm{CFsoil}=\text { faktor koreksi jenis tanah } \\
& \text { SFwater regime = scaling factor untuk } \\
& \text { water regime }
\end{aligned}
$$
SFwater regime $=$ scaling factor untuk water regime

Nilai lokal yang digunakan dalam penelitian ini adalah faktor emisi lokal untuk jenis padi lokal di lahan sawah Indramayu (Pantura Jawa) $)^{4}$.

\section{b. Sektor Energi}

Untuk sektor energi khususnya pada pembakaran bahan bakar fosil, tingkat emisi akan tergantung pada jumlah dan jenis bahan bakar, fraksi oksidasi bahan bakar, dan kandungan karbonnya. Menurut IPCC guideline, untuk menghitung emisi $\mathrm{CO}_{2}$ harus didapatkan dahulu; (1) data berbagai jenis penggunaan bahan bakar fosil, (2) koefisien kandungan karbon, (3) karbon yang tersimpan dalam produk untuk jangka waktu 
tertentu, ${ }^{4)}$ persen karbon teroksidasi selama pembakaran. Bila data keseluruhan diperoleh maka dengan matematika sederhana akan didapatkan Net Carbon Emission-nya.

Dalam menghitung emisi Gas Rumah Kaca (GRK) pada umumnya dapat digunakan persamaan sederhana sebagai berikut ${ }^{5)}$;

Emisi GRK, bhn bakar = Konsumsi Energi bhn bakar * Faktor Emisi GRK, bhn bakar ....

dimana,

Emisi GRK, bhn bakar = Emisi GRK seperti $\mathrm{CO}_{2}, \mathrm{CH}_{4}, \mathrm{~N}_{2} \mathrm{O}$ dari hasil pembakaran bahan bakar fosil .

Konsumsi Energi bhn bakar $=$ Konsumsi Energi Fosil

Faktor Emisi GRK, bhn bakar = Faktor Emisi GRK CO$~_{2}, \mathrm{CH}_{4}, \mathrm{~N}_{2} \mathrm{O}$ dari hasil pembakaran bahan bakar fosil

\section{c. Sektor Industri}

Penghitungan emisi sektor industri proses akan dilakukan dengan menggunakan metodologi berdasarkan pada metodologi IPCC Good Practice Guidelines (IPCC 1997a, b, c, 2000a), World Resource Institute/ World Business Council for Sustainable Development (WRI/WBCSD) (WRI 2001, 2004a), perhitungan emisi carbon dari UNEP serta metodologi dari U.S. EPA(USEPA 2003). Pada penelitian ini hanya akan dihitung pada 4 (empat) jenis industri lahap energi (intensive energy uses) yakni semen, baja, pulp \& kertas dan tekstil. Formula penghitungan secara umum dalam sektor industri adalah :

$\mathrm{CO}_{2}$ emisi $=\mathrm{M}$ produk (ton produk/tahun ) $\mathrm{x}$ $\mathrm{FE}$ (ton $\mathrm{CO}_{2}$ /ton produk) x FKM....(6)

Dimana ;

$\mathrm{M}$ produk = berat produk yang dihasilkan per tahun (ton)

$\mathrm{FE}=$ Faktor emisi dalan ton $\mathrm{CO}_{2}$ per ton produk

FKM $=$ Faktor Koreksi Metana (\%)

\section{d. Sektor Limbah}

Merujuk pada 2006 IPCC Guidelines, emisi $\mathrm{CH}_{4}$ dari timbulan sampah di TPA dihitung dengan formula1);

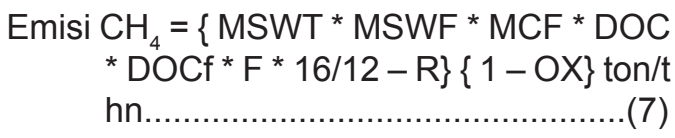

dimana,

MSWT = total produksi sampah (ton/ tahun)

MSWF = fraksi sampah dibuang ke TPA

MCF = Methane Correction Factor

DOC = Degradable Organic Carbon

DOCf $=$ Fraksi DOC disimilated

$\mathrm{F}=$ fraksi $\mathrm{CH}_{4}$ di TPA

$\mathrm{R}=$ recovered $\mathrm{CH}_{4}$

$\mathrm{OX}=$ fraksi oksidasi

Nilai-nilai lokal yang digunakan dalam perhitungan adalah komposisi sampah dan laju timbulan perkotaan yang didapat dari rerata atas survei komposisi sampah di 3 (tiga) kota yakni Bandung, Yogyakarta dan Piyungan ${ }^{4}$.

Sedangkan untuk emisi $\mathrm{CH}_{4}$ dari sub sektor limbah domestik dihitung formula sbb:

$$
\begin{array}{r}
\text { Emisi } \mathrm{CH}_{4}=\Sigma \mathrm{i}, \mathrm{j}\left(\mathrm{Ui}{ }^{*} \mathrm{Ti}, \mathrm{j}{ }^{*} \mathrm{EFij}\right) \times(\mathrm{TOW}-\mathrm{S}) \\
-\mathrm{R} \text { kg CH} \mathrm{CH}_{4} / \text { tahun......................... (8) }
\end{array}
$$

TOW = Total organik dalam limbah cair pada tahun inventarisasi, $\mathrm{kg}$ BOD $\mathrm{CH}_{4}$

$\mathrm{S}=$ Komponen organik yang disisihkan sebagai lumpur (sludge) pada tahun inventarisasi, $\mathrm{kg} \mathrm{BOD/tahun}$

$\mathrm{Ui}=$ Fraksi populasi pada di golongan pendapatan i pada tahun inventarisasi

Tij = Tingkat utilisasi sistem/ jalur pengolahan dan pembuangan, 
j, untuk tiapfraksi golongan pendapatan i pada tahun inventarisasi

$\mathrm{i}$ = golongan pendapatan: urban, low income - rural, high income - rural

$\mathrm{j}$ = Tiap jalur/sistem pengolahan/ pembuangan

EFij = faktor emisi, $\mathrm{kg} \mathrm{CH}_{4} / \mathrm{kg} \mathrm{BOD}$

$\mathrm{R}=$ Banyaknya recovery/pemanfaatan $\mathrm{CH}_{4}$ pada tahun inventarisasi, $\mathrm{kg} \mathrm{CH}_{4}$ /tahun

Nilai-nilai lokal yang digunakan dalam perhitungan adalah komposisi sampah dan laju timbulan perkotaan yang didapat dari rerata atas survey komposisi sampah di 3 (tiga) kota yakni Bandung, Yogyakarta dan Piyungan ${ }^{4}$.

\section{HASIL DAN PEMBAHASAN}

Perhitungan emisi GRK $\left(\mathrm{CO}_{2}\right.$ dan $\left.\mathrm{CH}_{4}\right)$ dilakukan dengan memasukkan data-data yang didapat dari tahun 2001-2006 ke dalam formula yang sudah disepakati dalam IPCC method. Dalam 2006 IPCC Guidelines sebenarnya ditetapkan secara lebih rinci untuk tiap sektor seperti jenis dan tipe hutan, jenis industri dan sebagainya. Mengingat keterbatasan waktu dan biaya serta tidak tersedianya data-data yang dipersyaratkan, maka beberapa sub sektor tidak dapat dihitung. Ini menyebabkan total emisi GRK nasional sebesar 827.058.035 Gg/tahun $\mathrm{CO}_{2}$ eq Gg/tahun (Tabel 1) diperkirakan hanya $60 \%$ dari angka emisi sebenarnya jika seluruh sektor dan sub sektor dalam IPCC dihitung (gambar 1).

Dari angka emisi total tersebut hampir $58 \%$ nya berasal dari sektor kehutanan sebesar $480.000 \mathrm{CO}_{2}$ eq Gg/tahun, dimana emisi total sebesar $821.000 \mathrm{CO}_{2} \mathrm{eq} \mathrm{Gg/}$ tahun dan kemampuan uptake sebesar $341.000 \mathrm{CO}_{2}$ eq $\mathrm{Gg} /$ tahun. Kelemahan dalam perhitungan ini adalah dengan menganggap hutan kita homogen, padahal dalam kenyataannya terdapat perbedaan kemampuan menyerap karbon maupun besaran emisi dari tiap jenis hutan atau tipe kawasan. Selain itu ada satu sumber emisi karbon yang cukup besar dari sektor hutan ini yaitu kebakaran lahan gambut (peat fire) yang tidak dihitung dalam tulisan ini sehingga bisa diperkirakan emisi GRK dari sektor hutan bisa lebih tinggi lagi. Beberapa tipe kawasan seperti forest land, crop land, grass land, wetlands dan settlements menurut IPCC harus dihitung secara terpisah, namun pengklasifikasian ini agak menyulitkan untuk

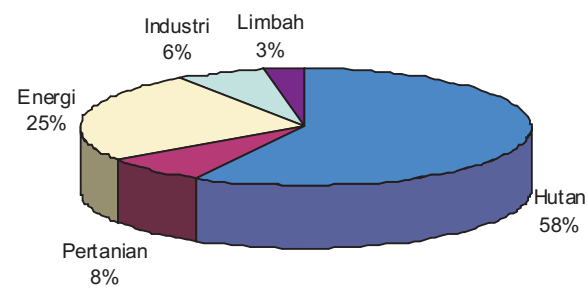

Gambar 1. Kontribusi emisi GRK (dalam $\mathrm{CO}_{2}$ e $\mathrm{Gg}$ /tahun) tiap sektor

Indonesia karena kita punya data luasan jenis hutan dengan definisi yang berbeda.

Penyumbang emisi GRK kedua terbesar adalah energi sebesar 207.179 $\mathrm{CO}_{2}$ eq Gg/tahun (25\%). Komponen terbesar dalam sektor energi adalah penggunaan dalam industri khususnya yang lahap energi yakni sebesar $49.645 \mathrm{CO}_{2}$ eq $\mathrm{Gg} / \mathrm{tahun}$ dan diikuti transportasi sebesar $44.970 \mathrm{CO}_{2}$ eq

$\square$ Hutan $\square$ Pertanian $\square$ Energi $\square$ Industri $\square$ Limbah

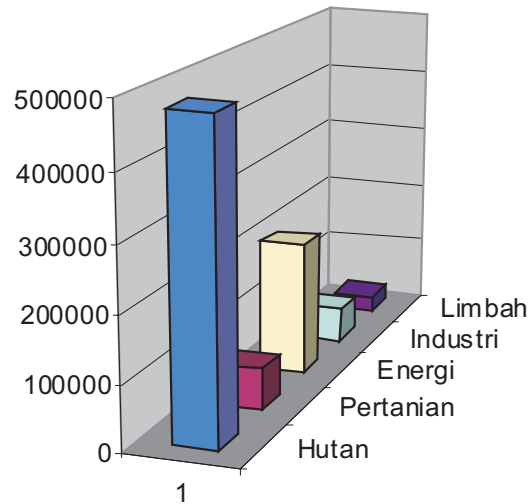

Gambar 2. Besaran emisi $\mathrm{CO}_{2}$ eq tiap sektor per tahun 
Tabel 1. Hasil Penghitungan Rata-rata Emisi GRK (Data 2001 - 2006)

\begin{tabular}{|c|c|c|c|c|}
\hline No & Sektor/Sub sektor & $\begin{array}{c}\mathrm{CO}_{2} \\
\text { (Gg/thn) }\end{array}$ & $\begin{array}{c}\mathrm{CH}_{4} \\
\text { (Gg/thn) }\end{array}$ & $\begin{array}{c}\mathrm{CO}_{2} \mathrm{eq} \\
\text { (Gg/thn) }\end{array}$ \\
\hline \multirow[t]{2}{*}{1} & Kehutanan & & & \\
\hline & - Hutan (campuran) & 480.000 & - & 480.000 \\
\hline \multirow[t]{3}{*}{2} & Pertanian & & - & \\
\hline & - Peternakan & 680 & - & 680 \\
\hline & - Lahan sawah & 62.000 & - & 62.000 \\
\hline \multirow[t]{7}{*}{3} & Energi & & & \\
\hline & - Rumah tangga & 23.595 & - & 23.595 \\
\hline & - Komersil & 3.602 & - & 3.602 \\
\hline & - Transportasi & 44.970 & - & 44.970 \\
\hline & - Pembangkit listrik & 82.253 & - & 82.253 \\
\hline & - Coal mining & & 148 & 3.114 \\
\hline & - Industri lahap energi & 49.645 & - & 49.645 \\
\hline \multirow[t]{5}{*}{4} & Industri Proses & & & \\
\hline & - Produk kapur & 2.356 & - & 2.356 \\
\hline & - Besi \& baja & 11.980 & - & 11.980 \\
\hline & - Semen & 28.803 & - & 28.803 \\
\hline & - Ammonia & 9.120 & - & 9.120 \\
\hline \multirow[t]{4}{*}{5} & Limbah & & & \\
\hline & - Sampah di TPA & - & 609 & 12.800 \\
\hline & - Limbah cair domestik & - & 578 & 12.140 \\
\hline & Total & & & 827.058 \\
\hline
\end{tabular}

Sumber : Hasil perhitungan

$\mathrm{Gg} /$ tahun serta rumah tangga sebesar $24.793 \mathrm{CO}_{2}$ eq Gg/tahun.

Untuk sektor industri umumnya emisi sebagian besar berasal dari penggunaan energi khususnya bahan bakar minyak dan listrik. Namun penggunaan energi di industri, emisinya dihitung sebagai emisi sektor energi. Hasil penghitungan emisi untuk industri yang berasal dari proses industri adalah $827.058 \mathrm{CO}_{2}$ eq $\mathrm{Gg} /$ tahun atau $6 \%$ dari keseluruhan sektor yang dihitung dalam penelitian ini. Industri semen merupakan industri yang paling besar mengeluarkan emisi karbon diikuti industri ammonia dan besi baja. Khusus untuk sektor industri ini hasil perhitungan bukan berasal dari data produksi tetapi dari pengukuran langsung di industri sampel. Menurut 2006 IPCC guidelines, sektor industri proses ini setidaknya harus dihitung pada 30 jenis industri, namun dalam penelitian ini hanya dihitung atas pengukuran emisi di 4 jenis industri utama.

Untuk sektor limbah, setidaknya harus diukur beberapa sub sektor dalam 2006 IPCC Guidelines yakni, sampah terbuang ke TPA, pengolahan sampah secara biologis, pembakaran sampah (baik 
insinerasi terkendali maupun open burning), limbah cair domestik dan industri. Dalam penelitian ini hanya akan dihitung emisi GRK dari sampah yang dibuang ke TPA dan limbah cair domestik ${ }^{1)}$. Pengolahan sampah secara biolgis dapat diabaikan mengingat kuantitasnya yang masih sangat kecil di Indonesia demikian pula pembakaran dengan insinerator. Sedangkan pembakaran sampah secara terbuka walau secara visual sering dilakukan di Indonesia namun data pasti sulit didapat, sehingga emisinya tidak diperhitungkan dalam penelitian ini.

Hasil penghitungan emisi $\mathrm{CH}_{4}$ di TPA sampah menghasilkan angka $609 \mathrm{Gg} /$ tahun atau setara $12.800 \mathrm{CO}_{2}$ eq Gg/tahun. Hasil ini tergolong besar dan berpotensi bagi pemanfaatan gasbio lebih lanjut. Sedangkan limbah cair domestik menghasilkan emisi $\mathrm{CH}_{4} 578 \mathrm{Gg} /$ tahun atau setara dengan $12.140 \mathrm{CO}_{2}$ eq Gg/tahun. Besarnya angka emisi dari sektor limbah cair domestik sama sekali tidak mencerminkan potensi pemanfaatan gasbio mengingat sifatnya yang menyebar di tiap pemukiman penduduk (spot), artinya emisi per titik sebenarnya kecil namun ada banyak jumlah titik emisi. Potensi pemanfaatan gasbio pada limbah cair adalah pada sub sektor industri khususnya industri agro seperti kelapa sawit dan tapioka.

\section{KESIMPULAN}

- Hasil penghitungan emisi Gas Rumah Kaca dalam penelitian adalah 827.058 $\mathrm{Gg} /$ tahun dalam $\mathrm{CO}_{2}$ equivalent. Angka ini diperkirakan baru $60 \%$ dari angka sebenarnya mengingat belum akuratnya penghitungan di sektor kehutanan dengan tidak dihitungnya emisi dari kebakaran lahan gambut (peat fire) yang besar di Indonesia.

- Dari keseluruhan sektor, sektor kehutanan merupakan penyumbang emisi $\mathrm{CO}_{2}$ ekivalen terbesar (58\%), diikuti sektor energi (25\%), pertanian $(8 \%)$, industri $(6 \%)$, dan limbah (3\%).

- Untuk sektor industri sendiri, industri semen masih merupakan kontributor emisi $\mathrm{CO}_{2}$ terbesar yakni $65 \%$, sedangkan di sektor energi paling tinggi adalah emisi dari kegiatan pembangkit listrik disusul transportasi.

- $\quad$ Proporsi distribusi emisi per sektor tersebut dapat berubah jika cakupan perhitungan dan tersedianya data yang lebih lengkap.

\section{DAFTAR PUSTAKA}

1. WMO-UNEP, 2007, Climate Change 2007 - The Physical Science Basis, IPCC Report

2. National Geographic, 2008, Perubahan Iklim, Edisi Spesial

3. $\mathrm{KLH}, \mathrm{UNDP}, 2009$, Indonesian National Greenhouse Gas Inventory under the UNFCCC, Enabling Activities for the Preparation of Indonesia's Second National Communication to the UNFCCC.

4. Purwanta, W., 2008, Studi Neraca GRK di Indonesia, Laporan Akhir Kegiatan (Technical Document TD03), TPSA-BPPT

5. Eggleston S., L. Buendia, M. Kyoko, T. Ngara, 2006, "2006 IPCC Guidelines for National Greenhouse Gas Inventories", Vol 5 Waste, IGES 